Original Research Paper

\title{
Evaluation of Relationships Between Some Growth Traits Measured at Birth and Weaning in South African Non- Descript Goat Kids using Canonical Correlation Analysis
}

\author{
Kwena Mokoena and *Thobela Louis Tyasi \\ School of Agricultural and Environmental Sciences, Department of Agricultural Economics and Animal Production, \\ University of Limpopo, Private Bag X1106, Sovenga 0727, Limpopo, South Africa
}

\author{
Article history \\ Received: 27-04-2021 \\ Revised: 11-06-2021 \\ Accepted: 15-06-2021 \\ Corresponding Author: \\ Thobela Louis Tyasi \\ School of Agricultural and \\ Environmental Sciences, \\ Department of Agricultural \\ Economics and Animal \\ Production, University of \\ Limpopo, Private Bag X1106, \\ Sovenga 0727, Limpopo, South \\ Africa \\ Email: louis.tyasi@ul.ac.za
}

\begin{abstract}
The study was conducted to assess the association among 6 different growth traits viz; X set- Birth Weight (BW), Heart Girth (HG), Rump Height (RH), Sternum Height (SH), Body Length (BL), Withers Height (WH), assessed at birth and viz; Y Set- Heart Girth (HG_3), Body Length (BL_3), Rump Height (RH_3), Weaning Weight (WW), Withers Height (WH_3), Sternum Height (SH_3) at weaning Measured in fifty $(n=50)$ non-descript goat kids. Pearson's correlation and canonical correlation analysis were employed, outcome of Pearson's highlighted that BW had a positive highly statistical correlation with WW $\left(\mathrm{r}=0.85^{* *}\right), \mathrm{WH}_{-} 3(\mathrm{r}=$ $0.61 * *)$ and SH_3 $(\mathrm{r}=0.83 * *)$ at $\mathrm{P}<0.01$. Results of canonical correlation showed an estimated canonical correlation coefficient $(\mathrm{r}=0.881)$ that was significant among the first pair of canonical variables $(\mathrm{P}<0.01)$. The results indicated that $\mathrm{WH}$ and $\mathrm{HG}$ had a greater contribution to the explanatory capacity of canonical correlation estimation at birth while BL_3 and RH_3 contributed mostly at weaning of non-descript goats. The findings of the study suggest that the heart girth and withers height might be used at birth as criteria for genetic improvement in non-descript goat kid's selection.
\end{abstract}

Keywords: Birth Weight, Canonical Weights, Canonical Variable, Canonical Correlation Coefficient

\section{Introduction}

South African non-descript goats are important to the communal farmers as they provide income and demand less capital for treatments and feed-supplement as they are hardy, resistant to diseases, good forager, well adapted to the harsh environment and fertile from a young age (Tyasi et al., 2020; Norris et al.,2015). Economic important traits that can be used in selection for improvement of the herd include bodyweight (Hagos, 2016; Iqbal et al., 2013; Tsegaye et al., 2013). Determining the association between two or more traits at birth and weaning is important in improving selection (Sahin et al., 2011). Many researchers prefer the simple correlation to determine the association and degree of association between body measurement traits (Berhe, 2017; Patbandha et al, 2018). However, the interrelationship among one or more variables makes it difficult to pinpoint the significance of the correlation (Tahtali et al., 2012). Çankaya and Kaylaap, (2007) define canonical correlation as the technique used to describe the relation between two sets of variables by calculating a linear combination that is having maximum correlation. The canonical correlation has been used to describe the relationship among birth weight and weaning weight in German sheep breeds (Çankaya and Kaylaap, 2007), reproduction and production traits of meat-type quails (Ribeiro et al., 2016), milk and wool yield in Akkaraman sheep in previous livestock studies (Karadavut, 2020). However, to our knowledge, there is no study estimating the relationship using the canonical correlation technique in Non-descript goats. Hence, the objectives of the paper were to (1) investigate the interrelationship between the six different body measurement traits at birth and weaning; (2) to explore which traits might be used at birth as selection criteria to improve the live body weight of non-descript goats at birth and weaning. This study will assist small stock farmers to identify interrelation among growth traits and making a good decision when selecting traits to improve the live body weight at birth and weaning. 


\section{Material and Methods}

The research was accomplished in a research area as outlined by Alabi et al. (2012). The experimental animals were a total of fifty (50) South African non-descript goat kids. A weighing scale was used to measure Body Weight (BW) while growth traits, namely Body Length (BL), Sternum Height (SH), Heart Girth (HG), withers height (WH) and Rump Height (RH) were measured at birth and weaning using a tape and a wooden ruler calibrated in centimetres. The measuring of the entire growth traits was carried out as described by Norris et al., 2015. Birth weight was measured after 24 hours and weaning weight was measured at three months of age. All the goat kids were weighed 24 hours after birth and ear-tagged. The goat kids were kept with their dam in the kraal with other goats. The kids were left in the kraal with does overnight; the only time the kids were separated from the does was when the does were released for grazing.

\section{Canonical Correlation Analysis (CCA)}

Canonical correlation technique was performed as described by Tahtali et al. (2012). Briefly, body measurement traits at birth were set as X-Set while body measurement traits at weaning were set as Y-Set. Interpretation of the canonical correlation was performed following the procedure of Sahin et al. (2011).

The null and alternative hypotheses for assessing the statistical significance of the canonical correlation coefficients are:

$H_{0}: \rho_{1}=\rho_{2}=\ldots=\rho_{r}=0$

$H_{1}: \rho_{1} \neq 0$ I at least one $i=1,2, r$ is:

The $F$ test statistic for the statistical significance of $\rho_{i}^{2}$

$$
F=\frac{1-\lambda_{1}^{\frac{1}{t}}}{\lambda_{1}{ }^{\frac{1}{t}}} \frac{s d_{2}}{s d_{1}} \sim f s d_{1}, s d_{2} \alpha
$$

Here:

$$
\begin{aligned}
& \lambda_{i}=\prod_{i=1}^{s}\left(1-r_{i} 2\right) ; s=\min (p, q) ; s d_{1}=p q ; s d_{2} \\
& =w t-\frac{1}{2} p q+1 ; w=n-\frac{1}{2}(p+q+3) ; t=\sqrt{\frac{p^{2} q^{2}-4}{p^{2} q^{2}-5}}
\end{aligned}
$$

Where:

$N=$ The number of cases,

$\rho=$ The number of variables in the $X$ set,

$q=$ The number of variables in the $Y$ set,

$r_{i} 2$ : represents the eigenvalues of $\sum_{1}^{-1} \sum \sum_{2}^{-1} \sum 2$ or the squared canonical correlations.

\section{Statistical Analysis}

All the computational work was accomplished using Statistical Package for Social Sciences statistical software version 26 IBM SPSS, 2019. Descriptive statistics such as means and standard deviation were analysed for a summary of the measured traits. Pearson's correlation was used for phenotypic correlation among measured traits. A Canonical correlation was used for all the canonical correlation analysis.

\section{Results}

The descriptive statistics for the examined traits at birth and weaning are shown in Table 1 while Table 2 shows a correlation among growth traits. Descriptive statistics indicated that WW mean value $(15.2 \pm 22)$ was greater than the mean value of $\mathrm{BW}(3.77 \pm 1.0)$. Descriptive statistic for measured traits shows that all traits measured at weaning have greater mean value than all traits measured at birth. Correlation, highest correlations $(\mathrm{P}<0.01)$ were estimated among $\mathrm{HG}$ and $\mathrm{WH}$ $(\mathrm{r}=0.82)$ at birth; $\mathrm{RH} \_3$ and $\mathrm{BL} \_3(\mathrm{r}=0.80)$ at weaning; and $\mathrm{WW}$ and $\mathrm{BW}(\mathrm{r}=0.80)$ for interrelationships between birth and weaning. The lowest correlations $(\mathrm{P}<0.05)$ were estimated among $\mathrm{HW}$ and $\mathrm{BW}(\mathrm{r}=0.03)$ at birth; WH_3 and RH_3 $(\mathrm{r}=0.22)$ at weaning period; BL_3 and $\mathrm{SH}(\mathrm{r}=0.04)$ for interrelationships among birth and weaning, respectively.

Although studies show that birth time is essential indicators of weaning, it is challenging to explain the association among the traits simultaneously. For this cause, six canonical correlation coefficients were predicted to describe the interdependence among the studied variable set, since the number of canonical correlations that need to be explained is the lowest number of traits at birth or weaning period (Table 3). The likelihood ratio test shows a significant at first canonical correlation coefficient $(\mathrm{r}=0.881)(\mathrm{P}<0.01)$. The results indicate the relation among the first canonical correlation variables $\left(\mathrm{U}_{1}\right.$ and $\left.\mathrm{V}_{1}\right)$.

Canonical weights were specified for the first pair of canonical variables in Table 4.

The coefficients highlight the outcome that birth has on the weaning. On that account, the variables can be used to come up with defined optimal linear combinations with the use of standardized canonical coefficients as, $\mathrm{U}_{1}=(-$ $0.97 \mathrm{BW})-(0.05 \mathrm{HG})+(0.04 \mathrm{RH})-(0.15 \mathrm{BL})+(0.07 \mathrm{WH})$ $-(0.06 \mathrm{SH}) \mathrm{V}_{1}=(-1.00 \mathrm{WW})-\left(0.22 \mathrm{HG} \_3\right)-\left(0.30 \mathrm{RH} \_3\right)$ $+\left(0.46 \mathrm{BL} \_3\right)-\left(0.14 \mathrm{WH} \_3\right)+\left(0.09 \mathrm{SH} \_3\right)$

Consistently, if the values of $\mathrm{BW}, \mathrm{HG}, \mathrm{BL}$ and $\mathrm{SH}$ reduce at birth, the readings of $\mathrm{WW}, \mathrm{HG}_{-} 3, \mathrm{RH} \_3$ and WH_3 at weaning will reduce, meanwhile the readings of the BL_3 and SH_3 at weaning will increase. Variables with higher canonical loadings given more to the multivariate 
association among growth traits evaluated at birth and the weaning from non-descript goat kids (Table 5).

Withers height and sternum height were more influential informing $V_{1}$ compared to other characters and also in forming $U_{1}$ at birth according to loadings for the weaning time. Meanwhile, the cross-loadings suggest that WH_3 and WH gave the most to canonical variants $V_{1}$ and $U_{1}$, respectively (Table 6).
First canonical variables $U_{1}$ explained $21.2 \%$ of the overall difference in the birth set, while 0.165 redundancy measures propose that about $16.5 \%$ of the ratio was explained by canonical variable $V_{1}$. It was also found that the First canonical variables $U_{1}$ explained $29.5 \%$ of the overall difference in the weaning set, while 0.229 redundancy measures propose that about $16.5 \%$ of the ratio was described by canonical variable $U_{1}$ (Table7).

Table 1: Descriptive values for examined character $(n=50)$

\begin{tabular}{llll}
\hline For Birth Period & X Variable Set Mean $\pm \mathrm{SD}^{*}$ & For Weaning Period & Y Variable Set Mean \pm SD* \\
\hline Birth Weight (BW) & $3.7 \pm 1.0$ & Weaning Weight (WW) & $15.2 \pm 2.2$ \\
Heart Girth (HG) & $38.4 \pm 5.4$ & Heart Girth (HG_3) & $56.5 \pm 4.4$ \\
Rump Height(RH) & $36.0 \pm 4.1$ & Rump Height (RH_3) & $46.5 \pm 4.6$ \\
Body Length (BL) & $34.8 \pm 4.6$ & Body Length (BL_3) & $52.6 \pm 4.6$ \\
Withers Height (WH) & $35.8 \pm 4.0$ & Withers Height (WH_3) & $47.2 \pm 2.8$ \\
Sternum Height(SH) & $27.0 \pm 5.7$ & Sternum Height(SH_3) & $33.3 \pm 5.5$
\end{tabular}

*SD: Standard deviation

Table 2: Phenotypic correlation between traits weaning and birth

\begin{tabular}{|c|c|c|c|c|c|c|c|c|c|c|c|}
\hline & BW & HG & $\mathrm{RH}$ & BL & WH & $\mathrm{SH}$ & WW & HG_3 & RH_3 & BL_3 & WH_3 \\
\hline$\overline{\mathrm{HG}}$ & 0.21 & & & & & & & & & & \\
\hline RH & 0.24 & $0.48^{* *}$ & & & & & & & & & \\
\hline $\mathrm{BL}$ & 0.10 & $0.81^{* * *}$ & $0.32^{*}$ & & & & & & & & \\
\hline WH & 0.03 & $0.82^{* *}$ & $0.47^{* *}$ & $0.76^{* *}$ & & & & & & & \\
\hline $\mathrm{SH}$ & 0.04 & $0.76^{* *}$ & 0.19 & $0.74^{* *}$ & $0.81^{* *}$ & & & & & & \\
\hline WW & $0.85^{* *}$ & 0.28 & 0.21 & 0.18 & 0.09 & $0.64^{* *}$ & & & & & \\
\hline HG_3 & $0.61^{\text {** }}$ & 0.18 & 0.10 & 0.08 & 0.04 & 0.26 & $0.54^{* *}$ & & & & \\
\hline RH_3 & 0.22 & 0.22 & -0.02 & $0.28^{*}$ & 0.17 & 0.22 & -0.02 & $0.34^{*}$ & & & \\
\hline $\mathrm{BL}_{-} 3$ & 0.23 & 0.24 & 0.09 & 0.19 & 0.07 & 0.04 & $0.30^{*}$ & $0.54^{* * *}$ & $0.80^{* *}$ & & \\
\hline WH_3 & 0.06 & 0.18 & 0.14 & -0.22 & 0.07 & $0.52^{* *}$ & $0.54^{* *}$ & -0.02 & 0.22 & $0.28^{*}$ & \\
\hline SH_$\_3$ & $0.38^{* *}$ & -0.07 & -0.07 & 0.13 & -0.10 & $0.64^{* *}$ & -0.02 & $0.30^{*}$ & -0.16 & -0.03 & 0.32 \\
\hline
\end{tabular}

$\mathrm{BW}=$ body weight, $\mathrm{BL}=$ body length, $\mathrm{RH}=$ rump height, $\mathrm{WH}=$ withers height, $\mathrm{SH}=$ sternum height, $\mathrm{HG}=$ heart girth.

**. Correlation is significant at the 0.01 level (1-tailed)

*. Correlation is significant at the 0.05 level (1-tailed)

Table 3: Summary results for the CCA

\begin{tabular}{lllllll}
\hline Pair of canonical & Canonical correlation & Square canonical & Eigenvalue & DF & Likelihood ratio & Probability Pr>F \\
\hline $\mathrm{U}_{1} \mathrm{~V}_{1}$ & 0.881 & 0.776 & 3.479 & 36 & 0.134 & 0.000 \\
$\mathrm{U}_{2} \mathrm{~V}_{2}$ & 0.448 & 0.200 & 0.251 & 25 & 0.602 & 0.663 \\
$\mathrm{U}_{3} \mathrm{~V}_{3}$ & 0.430 & 0.184 & 0.227 & 16 & 0.753 & 0.742 \\
$\mathrm{U}_{4} \mathrm{~V}_{4}$ & 0.212 & 0.044 & 0.047 & 9 & 0.925 & 0.950 \\
$\mathrm{U}_{5} \mathrm{~V}_{5}$ & 0.178 & 0.030 & 0.033 & 4 & 0.968 & 0.847 \\
$\mathrm{U}_{6} \mathrm{~V}_{6}$ & 0.021 & 0.000 & 0.000 & 1 & 1.000 & 0.893 \\
\hline
\end{tabular}

Table 4: Standardized canonical coefficients for canonical variables

\begin{tabular}{|c|c|c|c|c|c|c|c|c|c|c|c|c|}
\hline \multicolumn{6}{|c|}{$X$ - Variable set } & \multicolumn{7}{|c|}{$\mathrm{Y}-$ Variable set } \\
\hline BW & HG & RH & BL & WH & $\mathrm{SH}$ & & WW & HG_3 & RH_3 & BL_3 & WH_3 & SH_3 \\
\hline-0.97 & -0.05 & 0.04 & -0.15 & 0.07 & -0.06 & $\mathrm{~V}_{1}$ & -1.00 & -0.22 & -0.30 & 0.46 & -0.14 & 0.09 \\
\hline
\end{tabular}

Table 5: Canonical loadings of the original variables with their canonical variables

\begin{tabular}{|c|c|c|c|c|c|c|c|c|c|c|c|c|c|}
\hline \multicolumn{7}{|c|}{$\mathrm{X}$ - Variable set } & \multicolumn{7}{|c|}{$\mathrm{Y}-$ Variable set } \\
\hline & BW & HG & RH & BL & WH & $\mathrm{SH}$ & & WW & HG_3 & RH-3 & BL_3 & WH_3 & SH_3 \\
\hline $\mathrm{U}_{1}$ & -0.98 & -0.34 & -0.24 & -0.27 & -0.16 & -0.18 & $\mathrm{~V}_{1 \mathrm{~s}}$ & -0.97 & -0.69 & -0.31 & -0.46 & -0.08 & -0.21 \\
\hline
\end{tabular}


Table 6: Cross loading of the original variables with opposite canonical variables

\begin{tabular}{|c|c|c|c|c|c|c|c|c|c|c|c|}
\hline \multicolumn{6}{|c|}{$X$ - Variable set } & \multicolumn{6}{|c|}{$\mathrm{Y}$ - Variable set } \\
\hline BW & HG & RH & BL & WH & SH & WW & HG_3 & RH_3 & BL_3 & WH_3 & SH_3 \\
\hline-0.87 & -0.30 & -0.21 & -0.24 & -0.14 & -0.16 & -0.86 & -0.61 & -0.27 & -0.40 & -0.07 & -0.19 \\
\hline
\end{tabular}

Table 7: The explained total variation ratio by canonical variables for the variable sets

\begin{tabular}{|c|c|c|c|c|c|}
\hline \multicolumn{3}{|c|}{$\mathrm{X}$-variable set } & \multicolumn{3}{|c|}{ Y-variable set } \\
\hline & Variance extracted & Redundancy & & Variance extracted & Redundancy \\
\hline $\mathrm{U}_{1}$ & 0.21 & 0.17 & $\mathrm{~V}_{1}$ & 0.30 & 0.23 \\
\hline
\end{tabular}

\section{Discussion}

The indigenous goats grow well under the harsh conditions and provide mainly milk, meat and cash income which is vital in the livelihood of rural people. The study firstly used Pearson's correlation to examine the association among growth traits at birth and weaning. The findings suggest that $\mathrm{HG}$ had a correlation with $\mathrm{WH}$ at birth weight, while BL_3 and RH_3 had a correlation at weaning time. Secondly, a canonical correlation was used to examine the interdependence among birth time and weaning time. WW and $\mathrm{BW}$ have shown interrelations. The lowest correlations were predicted between $\mathrm{HW}$ and BW for birth time; RH_3 and WH_3 for weaning. SH and BL_3 for the interdependence between birth and weaning time. This study has revealed that $\mathrm{WH}$ and $\mathrm{SH}$ were factors that had more influence in this relation. This information on results will assist the breeders to select the best animals at birth to improve performance at weaning. These findings are in line with several studies (Çankaya and Kayaalp, 2007; Tahtali et al., 2012; Ozen et al., 2021). Çankaya and Kayaalp, (2007) estimated the association between live weight (y set) and some morphological traits in German sheep breeds using canonical correlation. The estimated canonical correlation coefficient was significant. Ozen et al. (2021) used canonical correlation analysis to study the association among seven biometric traits evaluated at weaning time (X-Set) and six months age (Y-Set) in a multidimensional form from an overall of seventy-one male lambs. The generated canonical dimensions had seven pairs and only the first pair was deemed statistically significant. The growth traits measures are important in the improvement of live weight.

\section{Conclusion}

The current paper has found the relationship between growth traits at birth and weaning time. Withers height, heart girth, body length and body weight were the most prominent factors in this relation. This information will help farmers in the selection of the best animal at birth and weaning to improve the bodyweight of the animal. More research needs to be performed on goats as the literature is minimal.

\section{Acknowledgement}

We are grateful as authors to the experimental farmworkers for assistance in data collection at the University of Limpopo.

\section{Author's Contributions}

Mokoena Kwena: Fieldwork and draft of manuscript.

Thobela Louis Tyasi: Experimental design, data analysis, editing the manuscript and approved the final manuscript.

\section{References}

Alabi, O. J., Ngambi, J., Norris, D., \& Egena, S. (2012). Comparative study of three indigenous chicken breeds of South Africa: body weight and linear body measurements. https://doi.org/10.3923/aj.2012.220.225

Berhe, W. G. (2017). Relationship and prediction of body weight from morphometric traits in Maefur goat population in Tigray, Northern Ethiopia. J. Biom. Biostat, 8(5), 1-6. https://doi.org/10.4172/21556180.1000370

Çankaya, S., \& Kayaalp, G. T. (2007). Estimation of relationship between live weights and some body measurements in German farm $x$ hair crossbred by canonical correlation analysis. Hayvansal Üretim, 48(2). https://doi.org/10.29185/hayuretim.446178

Hagos, G. (2016). Estimation of live body weight from the linear body measurements of Begait goats in Western Tigray, Ethiopia. Journal of Natural Sciences Research, 6, 23-27. https://core.ac.uk/reader/234656350

Iqbal, M., Javed, K., \& Ahmad, N. (2013). Prediction of body weight through body measurements in Beetal goats. Pakistan Journal of Science, 65(4), 458. https://www.researchgate.net/publication/259288409

Karadavut, U. (2020). Estimation of canonical correlation method of relations between milk and wool yield traits in Akkaraman sheep. Journal of Global Innovations in Agricultural Sciences,8(1):43-47. https://doi.org/10.22194/JGIASS/8.889 
Norris, D., Brown, D., Moela, A. K., Selolo, T. C., Mabelebele, M., Ngambi, J. W., \& Tyasi, T. L. (2015). Path coefficient and path analysis of body weight and biometric traits in indigenous goats. Indian Journal of Animal Research, 49(5), 573-578. https://arccjournals.com/journal/indian-journal-ofanimal-research/B-255

Ozen, D., Kocakaya, A., \& Ozbeyaz, C. (2021). Estimating relationship between live body weight and type traits at weaning and six months of age in bafra lambs using canonical correlation analysis. JAPS: Journal of Animal \& Plant Sciences, 31(2). https://doi.org/10.36899/JAPS.2021.2.0226

Patbandha, T. K., Pata, B. A., Trivedi, S. P., Gohil, B. C., Boradiya, P. C., Sharma, A., \& Savalia, K. B. (2018). Evaluating phenotypic correlation between body weight and biometric traits of migratory goats. https://www.entomoljournal.com/archives/2018/vol 6issue1/PartH/5-6-309-143.pdf

Ribeiro, J. C., Silva, L. P. D., Caetano, G. D. C., Crispim, A. C., Pacheco, R. D. O., \& Torres, R. D. A. (2016). Canonical correlation analysis applied to production and reproduction traits of meat type quails. Ciência Rural, 46, 1289-1294. https://doi.org/10.1590/0103$8478 \mathrm{cr} 20150215$
Sahin, M., Cankaya, S., \& Ceyhan, A. (2011). Canonical correlation analysis for estimation of relationships between some traits measured at weaning time and six-month age in merino lambs. Bulgarian Journal of Agricultural Science, 17(5), 680-686. https://www.cabdirect.org/cabdirect/abstract/201230 32238

Tahtali, Y., Çankaya, S., \& Ulutas, Z. (2012). Canonical correlation analysis for estimation of relationships between some traits measured at birth and weaning time in Karayaka lambs. Kafkas Univ Vet Fak Derg, 18(5), 839-844. https://doi.org/10.9775/kvfd.2012.6578

Tsegaye, D., Belay, B., \& Haile, A. (2013). Linear body measurements as predictor of body weight in Hararghe Highland goats under farmers' environment: Ethiopia. Global Veterinaria, 11(5), 649-656. http://www.idosi.org/gv/gv11(5)13/24.pdf

Tyasi, T. L., Mathapo, M. C., Mokoena, K., Maluleke, D., Rashijane, L. T., Makgowo, K. M., ... \& Mathye, N. D. (2020). Assessment of relationship between body weight and morphological traits of South African nondescript indigenous goats. Journal of Animal Health and Production, 8(1), 32-39. http://dx.doi.org/10.17582/journal.aavs/2021/9.4.55 5.562 